Third Thessalian period, and living a nomad life which corresponds generally to the wanderings of the Dorians as recorded by Herodotus. In the late Macedonian period, relations between central Macedonia and Chalcidice were resumed. Either the older population had revived, or the fusion between the old and the new had become more complete.

Iron slag found at Vardaroftsa suggests that iron was worked before the coming of the. Mycenæans, and may have been the object of their coming. At the end of the period the Vardar Valley was overrun by Danubians, probably from Hungary, forcing some Macedonians to follow their ancestors into Thessaly.
In the Iron Age the former inhabitants and their descendants returned and revived their half-agricultural, half-mining mode of life. Relations with the Egean were not revived until the arrival of Greek colonists in Chalcidice.

As regards general conclusions, the evidence points to acceptance in Macedonia of the chronological scheme which holds good for Crete, the Islands, and mainland Greece; thus the evolution of Macedonia is parallel with that of the Agean, of which world it forms an integral part. The archæological results support the claim of the Macedonians to be Greeks.

\title{
Superhardening Hardened Steel by Magnetic Means.
}

TTHE increase in hardness which occurs with many work-hardened metals when they are subjected to a low-temperature annealing treatment is well known and is made use of in the arts. Mr. E. G. Herbert has now considered, in a paper read recently before the Iron and Steel Institute, the question as to whether it might not be possible to apply some stimulus other than such a heat-treatment to effect a similar result. In a magnetic material a possible means of achieving such an object is to subject the worked metal to repeated changes of magnetic polarity. When this is done, it is shown that the hardness is increased by the magnetic treatment to exactly the same extent as it is by annealing at the optimum temperature.

Such heat and magnetic treatments appear, therefore, to be strictly alternative processes, producing the same atomic rearrangement in the deformed material. Thus it was found that when the specimen which had been magnetically hardened was afterwards subjected to a low - temperature anneal, no further increase of hardness resulted, whilst a specimen, hardened by 'blueing', was not affected by magnetic means. As an indication of the order of the changes of hardness involved may be taken the case of a hardened steel which had originally a hard- ness number of 810 . When severely cold-worked, the hardness was increased to 935 , after which it was magnetically treated and was further hardened to 1060 .

Mr. Herbert also proposes an explanation of the many small critical points which have been observed in the physical properties of iron, steel, and many other metals and alloys as their temperature is raised. These critical points are clearly independent of any allotropic changes, and a satisfactory explanation has not hitherto been offered. It is now suggested that an explanation, in part at any rate, may be found on the following lines.

The space lattice of the substance must possess one or more natural vibrational periodicities and be capable of resonating to certain 'notes'. When the frequency of the vibrations of the atoms themselves corresponds with this periodicity of the lattice or with one of its harmonics, the lattice is forced into a resonant vibration. The fact that the atomic vibrations are not monochromatie is not considered to do more than to introduce complications since the lattice may correspond to a number of wires tuned to different notes. It is shown that, as would be expected, some at any rate of the critical points are temperatures of high true specific heat.
F. C. T.

\section{A Russian Expedition to Seistan.}

$A^{N}$ expedition was undertaken to Persia in 1925 by the cultivated as well as the wild local plants. In course of her journey she travelled as far as Seistan, and she has now published a general outline of the climate, geographical arrangement, situation, and water supply of this district (Izvestia of the State Russian Geographical Society, 60, 1928).

The Seistan district occupies the delta of the Guilmend River; being situated in the extreme southeastern corner of Persia, it lies on the borders of Afghanistan and Baluchistan and is separated from Khorossan by the Lut desert. Owing to the fact that it possesses extensive plots of cultivated land, it is in a position to supply Khorossan with wheat, cotton, melted butter, down, etc.

The author divides the Seistan district into the following regions :

(1) Northern and western portions, including the Neysar depressions, bordering in the south on the lakes Khamun-i-Farrakh and Khamun-i-Severak and on the lowland connecting them. This is a swamp country, overgrown with Phragmites and Typha. Aquatic plants are represented by Potamogeton and Vallisneria spiralis L. The inhabitants consist of Sayades and Maldars -half-savage tribes, who hunt, fish, and breed cattle.

(2) Riparian clayey strip of land, occupying the northern and western borders of mainland. The meagre vegetation consists of Aeluropus villosa Frin,
Cynodon dactylon, Cressa cretica, Alisma and Tamarix species. Patches of land absolutely deprived of vegetation and covered by a fragile saline crust are met with. The inhabitants - the Goudars-live by cattlebreeding and by capturing birds for the purpose of obtaining their feathers.

(3) The sandy region situated in the southern and the south-eastern portion of the country. The vegetation of the sandy dunes consists of Anthrophytum, undersized Tamarix, saline Schanginia baccata, Alhagi, Prosopis stefaniana, and Eragrostis megastachya. Nearer to the Guilmend River drifting sands, which sometimes bury entire villages, occur. The population consists of Baluchi, who occasionally grow wheat.

(4) The forest region of the delta of the Guilmend River. This is the most fertile part of the country and has an abundance of water; as such it is the centre of cotton cultivation. The forests consist of Tamarix dioica and other Tamarix species. All the cleared plots serve for the cultivation of cotton, millet, and wheat.

(5) The region of saline clayey soil, lying in the centre of the country. Here trade is brisk, and agriculture is flourishing, the principal cultivated plant being wheat.

The author gives a vivid account of the customs and various occupations of the population. A map of the botanico-geographical division of the country is appended. 